\title{
The Interaction Between Ideology and Translation
}

\author{
Jiajun Bian ${ }^{1, *}, \mathrm{Xia} \mathrm{Li}^{2}$ \\ ${ }^{1}$ College of Electronic Engineering, National University of Defense Technology.
${ }^{2}$ College of Electronic Engineering, National University of Defense Technology.
${ }^{*}$ Corresponding author. Email: georgesbian@ 163.com
}

ABSTRACT

Translations are done by translators who work in a certain culture at a certain time, therefore the cultural beliefs of the translators may influence their translation activities. Ideology plays a significant role in the shaping of translation; in turn, translation can also influence ideology in certain ways. They together form a dialectical relationship. This paper aims to illustrate the influence of ideology on translation and how they interact with each other.

Keywords: Translation, Ideology, Interaction.

\section{INTRODUCTION}

The word "ideology" appeared first in French as idéologie at the time of the French Revolution, when it was introduced by a philosopher, Destutt de Tracy, as a short name for what he called his "science of ideas," which he claimed to have adapted from the epistemology of the philosophers John Locke and Étienne Bonnot de Condillac, for whom all human knowledge was knowledge of ideas. ${ }^{[1]}$

Generally speaking, "ideology" refers to the systematic views and opinions of people (usually intellectuals) of a certain class, political party, or profession about the world and society. It is a popular belief in a certain country or group, hidden in its political behaviour or ideological thoughts. Philosophy, politics, art, aesthetics, religion, ethics, etc. are the various forms. At the same time, the systematic social and cultural beliefs and values of a person in a certain period of time is also under the category of ideology. Translation, as an activity of cross-language, cross-cultural communication, is undoubtedly subject to the influence and restriction of ideology, and there is a direct and complicated relationship between the two.

\section{THE INFLUENCE OF IDEOLOGY ON TRANSLATION}

Ideology is the product of a certain society and culture. Translation is a type of behaviour under a certain social and historical background. The translator is a person in a social background, and any of his translation activities should be constrained by the ideology of the mainstream society. This restriction comes from the publication censorship of the government and also from the personal political consciousness of the translator. In a society, translation has an inevitable relationship with the superstructure. Translation is a part of the elite culture. When the elites of the society are engaged in translation activities, their purpose itself has a strong ideological tendency.

The influence of ideology on translation is tremendous. Translation is not only the conversion of information between texts, but also a language activity dominated by external forces. This process is very complicated because it involves a dual ideology. That is to say, translation not only depends on the ideology of the translator, but is also affected by the ideology imposed on him by the "patronage", so the translation strategy adopted by the translator is strongly influenced by ideology. ${ }^{[2]}$ As a result, translation is a synthetical product of history, society and culture.

\subsection{The Influence of Ideology on the Selection of Translation Materials}

The selection of translation materials is directly affected by ideology. Any translation activity has a reason or purpose, and serves special groups, political aims or and economic benefits. It can also be out of the translator's interests and preferences. "All translations are ideological since the choice of a source text and the use to which the subsequent target text is put are determined by the interests, aims, and objectives of social agents". ${ }^{[3]}$ No matter which purpose, if one wants to publish the texts, he must meet the requirements and 
expectations of the publisher and the society. Of course, there are some translators who merely keep the translation to themselves, which is understandable. In both cases, if the translation is against the general beliefs of the country, it is either unacceptable or it takes time for people to accept. To sum up, the selection of translation materials is closely related to the general cultural beliefs of the target language. We can say that the selection process depends to a large extent on the ideology of the target language, and it also has a certain degree of influence on the development of ideology.

\subsection{The Influence of Ideology on the Translator's Selection of Translation Strategy}

\subsubsection{Foreignization and Domestication}

Translation strategies are necessary because the translator faces two major problems during translation: cultural difference and linguistic difference. Generally, there are two basic translation strategies, "domestication" and "foreignization". Foreignization, also known as foreignizing translation, is "the type of translation in which a target text is produced which deliberately breaks target conventions by retaining something of the foreignness of the original". Domestication, also known as domesticating translation, is "the translation strategy in which a transparent, fluent style is adopted in order to minimize the strangeness of the foreign text for target language readers". [4]

\subsubsection{The Selection of Translation Strategies}

Lefevere emphasized the important role of ideology in the selection of translation strategies, "on every level of the translation process, it can be shown that, if linguistic considerations enter into conflict with considerations of an ideological and/or poetological nature, the latter tends to win out". [5] This means translation is often done under the constraints of ideology, at least in terms of the selection of translation strategies.

Translation activities are affected by the ideology of the source language as well as by the ideology of the target language, so the translation and the original intention might conflict. These two ideologies may be compatible or mutually exclusive. The translator can choose from different translation strategies. However, sometimes things or phenomena in the ideology of the original language in a certain historical period can be unacceptable according to the ideology of the target language, but may be acceptable in other or may even be regarded as natural. In any case, translators often adopt a strategy centred on the target language and their cultural beliefs. He will use the domestication method to delete, add or modify the original text so that it can meet the expectations of the readers of the target language and they don't feel strange.

As a bridge between different cultures, translation is not only an activity of language interaction, but also an act of cultural interaction. Ideology and translation are interactive. During translation, translators should not only focus on being "faithful" to the original text, but should also examine factors beyond the text from a greater perspective. At the same time, they should not exaggerate the influence and role of ideology.

\subsection{The Influence of the Patronage's Ideology and the Reader's Ideology on Translation}

Patronage pays much more attention to the ideology in the translation materials than to its poetics. Translators must conform to the patronage and they have to adopt the correct ideology. They must by no means stray from the patronage's ideology. Therefore, translation is not always aimed for the natural equivalent with the original text, but rather a target text which suits the client's needs. That's why Lefevere said in Constructing Cultures: Essays on Literary Translation, "Translators must be traitors, but most of the time they don't know it, and nearly all of the time they have no other choice".

The reader is an indispensable link in literary activities, and is the key stage for a text to become a work. According to acceptance aesthetics and reader response theory, readers are the centre of literary activities and are in a dominant position in literary reading and reception. The realization of literary meaning depends on readers' active reading and readers' re-creation. The reason why a work is immortal is that readers of every age are studying that work carefully. Translation is no exception. It is influenced and restrained by the conversation between the translator and the target-language readers. During the translation process, the ideology of the target-language readers inevitably exerts its influence.

\subsection{The Influence of Ideology on the Rewriting of Translated Texts}

As Lefever wrote, "Translation is, of course, a rewriting of an original text. All rewritings, whatever their intention, reflect a certain ideology and a poetics and as such manipulate literature to function in a given society in a given way". ${ }^{[6]}$ Translation is the process of rewriting the source text, using the target language. The process of rewriting is intangibly affected by the translator's ideology, and at the same time it is mixed with the translation strategy chosen by the translator. When rewriting the original text, the translator is also creating another text, which reflects the ideology of a specific group in a specific period. Therefore, as the core part of the text rewriting, the rewriting of the 
original ideology is greatly influenced by the coercive ideology and ethnocentrism of the sponsor or authority.

\subsubsection{The Influence of Coercive Ideology}

For a sponsor or authority with the power of decision-making, not everything in the original text, including the cultural ideology, is consistent with their ideology. When dealing with this type of original cultural text, the sponsor or authority usually consciously delete, add, or completely rewrite the concepts in religion, philosophy, politics, moral principles, and aesthetics from the original text, based on their own specific ideological standards. It occurs in every culture.

\subsubsection{The Influence of Ethnocentrism}

Victor Hugo once wrote, "When you offer a translation to a nation, that nation will almost always look on the translation as an act of violence against itself." [7] Translations can be potentially threatening precisely because they confront the receiving culture with another, different way of looking at life and society, a way that can be seen as potentially subversive, and must therefore be kept out.

Luther also describes a case of ideological control when he accuses a "scribbler" of stealing his New Testament and says, "his prince, in a terrible preface, forbade the reading of Luther's New Testament and ordered the scribbler's New Testament read". ${ }^{[8]}$

Ethnocentrism refers to the practice of understanding and evaluating things in other countries in terms of the criteria and ideas of one's own country, including human behaviour, communication methods, social customs, management styles and social values.

For the coercive ideology of the translator or sponsor, the text is rewritten intentionally and consciously. For the ideology influenced by ethnocentrism, the strategy of text rewriting is often chosen unconsciously. People often take it for granted that their own national values, social rules, and language rules are more correct and more acceptable than other national ideologies. During the process of translation, foreign ideologies are inevitably subject to domestication. This is because "most literary translations must domesticate the original text if they want to influence the masses or at least the current literature in the local culture." Therefore, the dominant ideology of the culture in the target language will inevitably affect the rewriting process of the original ideology. This ideology unconsciously plays a vital role in the process of domestication.

However, it must be admitted that however great the influence of ideology on translation activities is, the nature of such influence is relative rather than absolute.
Therefore, we should not exaggerate the influence or manipulation so much as to forget the ontology of translation studies.

\section{THE INTERACTION BETWEN IDEOLOGY AND TRANSLATION}

\subsection{The Process of Translation is an Interaction with Ideology}

Translation, fundamentally speaking, is to import the ideology of foreign culture into the ideology of local culture. For the system of local values, this is a kind of foreign cultural penetration, which means destruction, subversion, and therefore a test of local culture. A strong superstructure will in turn use its own power to manipulate this external force; a weak superstructure will be helpless in the face of this external force, and will be either assimilated or subverted in the end. And those cultures that refuse to communicate with the outside world will only remain primitive, backward, and eventually go to extinction. For the translators, the translation activities are closely related to ideology. Translation activities must conform to the existing ideology of the target language and cannot exceed the boundaries of that ideology, as all societies have special ideological systems with implicit or explicit ideological boundaries. Therefore, translation is actually the result of the compromise between the two ideologies that conflict with each other. ${ }^{[9]}$

\subsection{The Influence of Translation Activities on Ideology}

In turn, translated texts can also influence the ideology and culture of a particular country. Let's look at the examples of some famous translators in China in the last two centuries, Yan $\mathrm{Fu}$, Lin Shu and Liang Qichao. Most of the texts translated by Yan Fu are originally western academic masterpieces, which contain advanced ideologies such as the theory of evolution, free economy, and civil liberties. These advanced ideologies have subverted the traditional mainstream ideology of China through Yan Fu's translation. These translated works have promoted the production of new ideologies to meet the needs of social development.

Lin Shu's literary translation mainly involves English literature. Because of his solid foundation of traditional Chinese culture and his love for Chinese culture, he focused on promoting and protecting local culture in the selection of texts and translation strategy. At the same time, however, he also introduced new things and new concepts. Through his introduction, the western culture was gradually recognized by the Chinese people. Lin's novels have also inspired a generation of readers to explore and understand western 
literature and culture, and have directly or indirectly influenced many modern writers such as Lu Xun, Zhou Zuoren, Guo Moruo, Mao Dun, Qian Zhongshu, and Bing Xin.

Another example is Liang Qichao, whose translation of western novels influenced social politics of the time. Liang Qichao translated political novels and poems, and directly participated in social and political struggles himself. The most important feature of his translation activities is "politics first, changing with time". The "change" is not only reflected in translation materials, but also in his translation features. However, the essence of patriotism and national salvation in his translation are consistent. It is precisely this point that enabled him to change the materials and strategy of translation in a timely manner to serve politics.

Liang Qichao's devotion in translation activities inspired people's wisdom and helped to save the nation from extinction; his choice of translation materials and application of translation strategies are all closely related to the national reality. His translation practice has proved the viewpoint of contemporary translation theorists: that the primary function of translation is social function rather than language function. Translation is not only a simple act of language conversion, but also a unique political and cultural act in the society of the target language. Under his political influence, more people with lofty ideals joined him. It not only promoted the development of modern Chinese literary translation, but also influenced the thinking of many Chinese people at the time. These examples show that translation can influence ideology in significant ways.

\section{CONCLUSION}

During the process of translation, the translator may actively conform to the mainstream ideology of the society, thereby deleting and correcting the text in the original text that conflicts with the mainstream ideology of the target language country. But the translators are not submissive to all ideologies of the target language culture. Translators with strong political consciousness, such as those in the late Qing Dynasty and in the early 20th century, tend to respond positively to these ideologies in foreign languages in order to transform the backward thinking of the society. Through these positive reactions, literary translation can influence the ideologies of the target language readers. The culture and ideology of the target language are compared with those of the source language, then they either change or evolve because of the latter. This process shows that ideology and translation can interact with and influence each other.

The influence of ideology on translation is constantly changing. The correct attitude is to recognize the manipulative or restrictive function of ideology on translation and avoid ideological generalization. However, since translation is a kind of cultural fusion, we should advocate the coexistence and complementarity of multilingualism and multiculturalism. We should gradually eliminate the manipulation of ideology on translation, make translation choices rationally, and promote cultural interaction and cultural construction of various ethnic groups.

\section{REFERENCES}

[1] https://www.britannica.com/topic/ideology-society.

[2] Edwin Gentzler, Contemporary Translation Theories. Shanghai : SFLEP, 2004.

[3] C. Schaffner. Third ways and new centers : Ideological unity or difference? In: $\mathrm{M}$. Calzada-Perez . (Ed. ), Apropos of ideology, Manchester: St. Jerome Publishing, 2003.

[4] Mark Shuttleworth \& Moira Cowie. Dictionary of Translation Studies. Manchester: St. Jerome Publishing, 1997 .

[5] Andre Lefevere \& Susan Bassnett. Constructing Cultures: Essays on Literary Translation. London: Multilingual Matters, 1997.

[6] Andre Lefevere. Translation, Rewriting, and the Manipulation of Literary Fame. London \&New York: Routledge, 1992.

[7] Victor Hugo. Oeuvres Completes de William Shakespeare. Paris: Garnier, 1865.

[8] Andre Lefevere. Translation/history/culture, a Source Book. New York: Routledge, 1992.

[9] Basil Hatim and Ian Mason. Translator as Communicator. London and New York: Routledge, 1997 . 